\title{
Transcutaneous abdominal ultrasonography in the staging of lung cancer
}

Per Sigvald Bakke, Marianne Taule, Elisabeth Lillo, Gunnar Melgren, Inger Johanne Magnussen, Ole Johan Halvorsen
Department of Thoracic Medicine P S Bakke

M Taule

E Lillo

G Melgren

Department of Radiology

I J Magnussen

Department of Pathology,

The Gade Institute O J Halvorsen

University Hospital of Haukeland, N-5021 Haukeland, Norway

Correspondence to: Dr P S Bakke.

Received 17 January 1996 Returned to authors 19 April 1996

Revised version received 10 October 1996 Accepted for publication 14 October 1996

\begin{abstract}
Background - There is limited information available regarding the relationship between clinical indicators of widespread disease in patients with lung cancer and the findings of transcutaneous ultrasonography.

Methods - A retrospective survey was made of 279 consecutive patients with lung cancer. By reviewing the patients' records the clinical findings were divided into symptoms, signs, and laboratory tests indicative of metastatic disease. All patients had been examined by abdominal ultrasonography.

Results - The patients included $19 \%$ with small cell carcinoma. The frequency of abdominal metastases by ultrasonography in those with small cell carcinoma was $40 \%$, in the other patients it was $8 \%$. Regardless of histological group, all the 40 patients with abdominal metastases by ultrasonography had at least one clinical category indicative of widespread disease and $38(95 \%)$ had two or all three clinical categories positive. Fifty nine patients had no clinical indicators of metastases and none of these had abdominal metastases by ultrasonography.

Conclusions - The results of this study indicate that abdominal metastases are found in lung cancer patients with clinical findings indicative of widespread disease. No abdominal metastases were found in patients with a negative clinical evaluation. The results indicate that transcutaneous ultrasonography of the abdomen is not necessary in the initial staging if the clinical evaluation is unremarkable.
\end{abstract}

(Thorax 1997;52:276-280)

Keywords: lung cancer, staging, ultrasonography.

Lung cancer is now the leading cancer in the male population of Europe and North America, and it is the cancer type showing the steepest increase in incidence in the female population. ${ }^{1}$ Cure of non-small cell lung cancer is only possible by surgical treatment. Small cell lung cancer is not often operable, but the extent of the disease may influence the type of chemotherapy and radiotherapy. Consequently, looking for metastases is an important part of the pretreatment assessment of both small cell and non-small cell lung cancer. Necroscopic studies have shown that lung cancer frequently spreads to the liver, adrenal glands, and abdominal lymph nodes. ${ }^{23}$

Studies have examined the relationship between clinical signs indicating widespread disease and the presence of abdominal metastases as assessed by computed tomographic (CT) scanning $^{4-10}$ and isotopic scanning. ${ }^{11-13}$ Few studies, however, have compared the clinical evaluation with the findings of transcutaneous abdominal ultrasonography, ${ }^{1415}$ and neither of these studies examined whether the relation ship between clinical signs and abdominal metastases varied with the type of lung cancer. In a recent meta-analysis of the usefulness of the clinical examination for detecting extrathoracic metastases in lung cancer such studies are encouraged. ${ }^{16}$

In our Department of Thoracic Medicine we routinely perform transcutaneous abdominal ultrasonography on all patients with newly diagnosed lung cancer. The objective of this study was to assess whether there is an association between clinical indicators of extensive disease and ultrasonographic signs of abdominal metastases in patients with lung cancer. Furthermore, we wanted to examine whether this relationship differed between patients with small cell and non-small cell lung cancer.

\section{Methods}

All patients with a histological diagnosis of lung cancer obtained at the Department of Thoracic Medicine at the University Hospital of Bergen, Norway during January 1990 to December 1992 were eligible. Patients who had lung cancer diagnosed at other hospitals and were transferred to our department for further treatment were not included.

The part of the patient record based on the clinical examination by the junior house officer at admission to hospital and the following examination by the pulmonary consultant were retrospectively reviewed to identify the presence or absence of clinical findings indicating metastatic disease. In cases of disagreement between the junior house officer and the consultant the findings of the latter were chosen. In addition, routine laboratory data were recorded. This information was categorised into symptoms elicited by history, signs at clinical examination, and laboratory data. Any abnormal finding was considered to represent an abnormality for the whole category. The clinical findings grouped by category were (1) symptoms: weight loss $>3 \mathrm{~kg}$ during the previous six months, focal skeletal pain, headache, nausea, focal weakness or paraesthesia, personality 
Table 1 Percentage distribution by histological type and stage at time of diagnosis

\begin{tabular}{llllll}
\hline Stage & $\begin{array}{l}\text { Total } \\
(n=279)\end{array}$ & $\begin{array}{l}\text { Small cell } \\
(n=52)\end{array}$ & $\begin{array}{l}\text { Squamous cell } \\
(n=98)\end{array}$ & $\begin{array}{l}\text { Adenocarcinoma } \\
(n=91)\end{array}$ & $\begin{array}{l}\text { Undifferentiated* } \\
(n=38)\end{array}$ \\
\hline I & 19 & 6 & 20 & 29 & 9 \\
II & 7 & 4 & 6 & 8 & 6 \\
IIIA & 20 & 15 & 24 & 17 & 24 \\
IIIB & 22 & 23 & 20 & 20 & 29 \\
IV & 33 & 52 & 29 & 26 & 32 \\
\hline
\end{tabular}

* This group includes six patients with large cell carcinoma and four patients with carcinoid tumour.

change; (2) signs at clinical examination: enlarged lymph nodes, hepatomegaly, bone tenderness, hoarseness, superior vena cava syndrome, focal neurological signs; (3) laboratory data: haemoglobin $<11 \mathrm{~g} / \mathrm{dl}$, any increase in serum levels of alanine aminotransferase (ALAT), aspartate aminotransferase (ASAT), gamma glutamyl transferase (GGT), or alkaline phosphatase (ALP). ALAT and ASAT were considered abnormal if $>50$ international units (IU) $/ \mathrm{ml}$, GGT > $100 \mathrm{IU} / \mathrm{ml}$, and ALP > 270 $\mathrm{IU} / \mathrm{ml}$.

The reviews of the clinical records of the eligible patients were performed by three of the authors (MT, EL, GM). To examine the intraobserver and inter-observer agreement of the data obtained 15 of the records were reviewed twice by each observer and 15 records were reviewed by all three without the reviewer's knowledge at what time during the field work this would happen. The intra-observer and inter-observer agreement for the various symptoms and signs varied between $80 \%$ and $93 \%$, being lowest for focal neurological signs, headache and nausea, and highest for hepatomegaly and hoarseness. However, as the presence of one symptom or sign was considered to represent an abnormality for the entire category, respectively, the inter-observer agreement when characterising the patients by category was $93 \%$. The corresponding figure for the intraobserver agreement was $100 \%$. The physicians who reviewed the journals were blinded to the findings of the imaging examinations.

Histological data of the tumour and the TNM classification ${ }^{17}$ were obtained for each patient. The $\mathrm{T}$ and $\mathrm{N}$ status was based on findings of a computed tomographic (CT) examination of the thorax. The $M$ status was, in addition, based on clinical findings and results of abdominal ultrasonography as well as results from brain and bone scanning. CT scanning of the thorax and abdominal ultrasonography were performed on all patients, while scans of the brain and bone were made only on clinical suspicion of brain and bone metastases, respectively.

The CT scans of the thorax and brain were performed with a second generation scanner (GE 9800). All scans were done with an intravenous injection of contrast for better enhancement, using a slice thickness of $1 \mathrm{~cm}$. The bone scans were performed four hours after intravenous injection of monodiphosphate labelled with technetium-99m. Scanning was done using a gamma camera (Diacam; Siemens). The thoracic and brain CT scans and the radionuclide bone scans were interpreted by experienced physicians.
Abdominal ultrasonography was performed using a gray scale ultrasonograph and a sector scanner of $5 \mathrm{MHz}$ (GE 3000RT and GE 3600RT). In cases of insufficient penetration a $3.5 \mathrm{MHz}$ scanner was used. The abdominal ultrasonographic examination was performed by junior and senior radiologists with ultrasonographic experience varying from a few months to 15 years. The junior physicians were supervised by senior radiologists.

The differences in the presence or absence of clinical indicators of widespread disease in patients with and without abdominal metastases were compared by $\chi^{2}$ analysis. Probability values of less than 0.05 were considered significant.

\section{Results}

Three hundred and nineteen patients were eligible for entry into the study. Of these, 40 were excluded either because the patient was too ill to go through a staging or not willing to do it $(n=23)$, the diagnosis was made after death $(n=10)$, there were incomplete data in the records $(n=5)$, or because records were missing $(\mathrm{n}=2)$.

Of the 279 patients included in the study $227(81 \%)$ were men. The mean (SD) age of the patients was 66 (13) years. Symptoms indicating widespread disease were seen in $67 \%$ of the patients while signs of widespread disease were noted in $36 \%$. Laboratory data indicative of abdominal metastases were noted in $41 \%$ of the patients. At least one of the categories was seen in $79 \%$, while at least two and all categories were noted in $48 \%$ and $18 \%$ of the patients, respectively.

The distribution of patients by histological type and stage by time of diagnosis is shown in table 1 . The non-small cell carcinomas amounted to $81 \%$ of the lung cancers. The patients with small cell carcinomas had a more advanced stage than those with non-small cell carcinomas $\left(\chi^{2}=10.41, \mathrm{p}<0.001\right)$.

Table 2 shows the frequencies of clinical categories in patients with small cell carcinomas and non-small cell carcinomas. The presence of all categories was noted three times as often in the small cell carcinoma group as in the nonsmall cell carcinoma group. In the latter a quarter of the patients were negative to all the clinical categories at the time of diagnosis while only two of the patients with small cell carcinoma were negative to all clinical categories (table 2).

Abdominal ultrasonography showed metastases in $19(8 \%)$ of the 227 patients with nonsmall cell carcinoma compared with $21(40 \%)$ 
Table 2 Clinical findings at time of diagnosis (\%)

\begin{tabular}{llll}
\hline Clinical findings & $\begin{array}{l}\text { Non-small } \\
\text { cell carcinoma } \\
(n=227)\end{array}$ & $\begin{array}{l}\text { Small cell } \\
\text { carcinoma } \\
(n=52)\end{array}$ & p value \\
\hline All 3 categories normal & 25 & 4 & $<0.05$ \\
Any 1 category abnormal & 33 & 23 & \\
Any 2 categories abnormal & 29 & 35 & $<0.05$ \\
All 3 categories abnormal & 12 & 39 &
\end{tabular}

Categories are defined in methods.

of the 52 with small cell carcinoma at the time of diagnosis $(\mathrm{p}<0.01)$. The metastatic lesions were located in the liver $(\mathrm{n}=32)$, the adrenal glands $(\mathrm{n}=7)$, and in both liver and adrenal glands $(n=1)$.

A comparison of the clinical findings with the presence or absence of abdominal metastases is shown in table 3. In the 59 subjects who had no signs, symptoms, or routine laboratory tests indicative of widespread disease, none had abdominal metastases by ultrasonography (95\% confidence interval (CI) $0 \%$ to $6 \%$ ). Hence, the predictive value of a negative clinical evaluation as to abdominal metastases was $100 \%$ (95\% CI $94 \%$ to $100 \%$ ) (table 4 ). The corresponding intervals given for non-small cell and small cell lung cancer separately were $92 \%$ to $100 \%$ and $79 \%$ to $100 \%$, respectively, the confidence intervals being wider due to smaller numbers in the subgroups. The positive predictive value of a clinical evaluation was much lower than the negative predictive value, and was higher in those with small cell than in those with non-small cell carcinoma (table 4).

There was no individual clinical finding within a category which was particularly predictive of abdominal metastases. In patients with non-small cell and small cell lung cancer the probability of metastatic abdominal lesions increased as the number of abnormal clinical categories increased (table 5).

Table 3 Clinical findings by histological type (small cell versus non-small cell carcinoma) in patients with and without abdominal metastases at time of diagnosis*

\begin{tabular}{|c|c|c|c|c|}
\hline & \multicolumn{2}{|c|}{ Non-small cell carcinoma } & \multicolumn{2}{|c|}{ Small cell carcinoma } \\
\hline & $\begin{array}{l}\text { Abdominal } \\
\text { metastases } \\
\text { absent }\end{array}$ & $\begin{array}{l}\text { Abdominal } \\
\text { metastases } \\
\text { present }\end{array}$ & $\begin{array}{l}\text { Abdominal } \\
\text { metastases } \\
\text { absent }\end{array}$ & $\begin{array}{l}\text { Abdominal } \\
\text { metastases } \\
\text { present }\end{array}$ \\
\hline All 3 categories normal & $57(28)$ & $0(0)$ & $2(6)$ & $0(0)$ \\
\hline Any 1 category abnormal & $74(36)$ & $2(11)$ & $12(39)$ & $0(0)$ \\
\hline Any 2 categories abnormal & $58(28)$ & $8(42)$ & $10(32)$ & $8(38)$ \\
\hline All 3 categories abnormal & $19(9)$ & $9(47)$ & $7(23)$ & $13(62)$ \\
\hline Total & $208(101)$ & $19(100)$ & $31(100)$ & $21(100)$ \\
\hline
\end{tabular}

* Categories are defined in methods.

Numbers in parentheses are percentages of total.
Table 5 Probability of abdominal metastases assessed with ultrasonography by clinical findings in patients with non-small cell carcinoma and those with small cell carcinoma*

\begin{tabular}{lccc}
\hline & $\begin{array}{l}\text { Non-small cell } \\
\text { carcinoma } \\
(\%)\end{array}$ & $\begin{array}{l}\text { Small cell } \\
\text { carcinoma } \\
(\%)\end{array}$ & p value \\
& $(\%)$ & 0 & \\
\hline All 3 categories normal & 0 & 0 & $<0.05$ \\
Any 1 category abnormal & 3 & 44 & 0.09 \\
Any 2 categories abnormal & 12 & 65 & \\
All 3 categories abnormal & 33 & &
\end{tabular}

* Categories are defined in methods.

\section{Discussion}

This study describes the comparison of a detailed clinical evaluation with the findings of abdominal ultrasonography in 279 consecutive patients with proven lung cancer. All the 40 patients with abdominal metastases identified by ultrasonography had symptoms, signs, or laboratory findings indicative of metastatic disease. Conversely, no abdominal metastases were found in the 59 patients who had no clinical indications of widespread disease.

Previous studies on patients with small cell lung cancer have observed abdominal metastases by CT scanning or ultrasonography in $34-37 \%$ at the time of diagnosis. ${ }^{1819}$ The corresponding figures for patients with nonsmall cell lung cancer vary between $8 \%$ and $22 \% .^{45-1014}$ These figures are in crude agreement with those of the present study. However, direct comparisons should be made with caution. In some of the studies cited the patients were selected for entry by clinical evaluation indicating operable disease,,$^{511}$ or by incompletely defined criteria. ${ }^{48-10}$ In contrast, the present study included consecutively al patients with lung cancer, regardless of stage, admitted to our department.

The results of the present study agree with those of previous surveys using isotopic scans ${ }^{11-13}$ and two recent studies using abdominal ultrasonography ${ }^{15}$ and abdominal CT scanning. ${ }^{7}$ All these studies concluded that the result of a clinical evaluation should determine the extent of the search for metastases in patients with lung cancer. In contrast, several other studies ${ }^{45-1014}$ have found occult metastases by routine ultrasonography or CT scanning in patients with non-small cell lung cancer regarded as resectable as evaluated by "history, clinical examination, chest radiography or bronchoscopy". The problem when assessing the results of these studies is that they do not define what is meant by a negative history and clinical examination. For instance, are weight $\operatorname{loss}^{20}$ and anaemia ${ }^{21}$ included in the criteria? It

Table 4 Sensitivity, specificity, and predictive values of the clinical evaluation in detecting abdominal metastases using ultrasonography as the gold standard.

\begin{tabular}{lllllll}
\hline & $\begin{array}{l}\text { No. of } \\
\text { patients }\end{array}$ & $\begin{array}{l}\text { Prevalence of } \\
\text { abdominal metastases } \\
(\%)\end{array}$ & $\begin{array}{l}\text { Sensitivity } \\
(\%)\end{array}$ & $\begin{array}{l}\text { Specificity } \\
(\%)\end{array}$ & $\begin{array}{l}\text { PPV } \\
(\%)\end{array}$ & $\begin{array}{c}\text { NPV } \\
(\%)\end{array}$ \\
\hline Small cell lung cancer & 52 & 40 & 100 & 6 & 42 & 100 \\
Non-small cell lung cancer & 227 & 8 & 100 & 27 & 13 & 100 \\
Total & 279 & 14 & 100 & 25 & 18 & 100 \\
\hline
\end{tabular}

$\mathrm{PPV}=$ positive predictive value; NPV = negative predictive value. 
is to be hoped that future studies comparing the clinical evaluation with various imaging techniques state precisely the criteria of the clinical evaluation. Only one study detecting occult metastases defined clearly a negative evaluation with respect to metastases in the liver, brain, and bone. ${ }^{14}$ This included 146 patients with non-small cell lung cancer and compared the clinical organ status with the findings of the imaging of that organ. With regard to the liver, $9 \%$ of those with a normal liver assessed clinically had metastases revealed by ultrasonography. In contrast, the present study required a total negative clinical status, regardless of organ, to define the patient as having an unremarkable clinical evaluation.

The rate of false positive liver metastases by ultrasonography is about $0-7 \% .{ }^{22}$ False positive findings may cause needless, dangerous and time-consuming diagnostic tests and, in the worst scenario, may prevent the patient from receiving a curative resection.

False negative abdominal ultrasonographic findings occur in $30-40 \%$ of patients with abdominal metastases. ${ }^{2223}$ If ultrasonography is omitted in patients with a negative clinical evaluation, additional false negative cases might occur. Based on our findings, these additional cases might amount to $0-6 \%$ of patients with no markers of advanced disease. Whether this justifies routine abdominal imaging may be questioned. ${ }^{16}$ In a recent review on the search for metastases in patients with lung cancer cost effectiveness analyses were requested, weighing the risk of false negative clinical evaluation against the problems caused by false negative imaging, false positive imaging, and the costs of routine screening. ${ }^{16}$

The predictive values of the positive clinical categories as to the presence of abdominal metastases were higher for patients with small cell carcinoma than for those with non-small cell carcinoma at the time of diagnosis. This was to be expected as the occurrence of abdominal metastases in the former histological group was much higher. For instance, in those with two abnormal categories eight of 66 patients with non-small cell cancers had metastases compared with eight of 18 with small cell cancers $\left(\chi^{2}=6.68, \mathrm{p}<0.01\right.$; table 3$)$. The predictive value of a positive test is dependent on the true prevalence of the factor being examined. ${ }^{24}$

The positive predictive value of the clinical evaluation was much lower than the negative predictive value (table 4). Our results indicate that ultrasonography is required to confirm the presence of metastatic disease in patients with an abnormal clinical finding, but only if such a confirmation has therapeutic consequences.

One could argue that potentially better techniques than ultrasonography, such as CT scanning or magnetic resonance imaging (MRI), would be able to detect smaller metastatic lesions. However, in a recent review comparing the ability of ultrasonography and CT scanning to detect liver lesions, the sensitivity for CT scanning was only slightly better than for ultrasonography. ${ }^{23}$ The sensitivity of the former varied between $57 \%$ and $82 \%$, and the latter between $58 \%$ and $71 \%$. The relatively low values of both methods are mainly due to difficulties in demonstrating foci of less than $1 \mathrm{~cm}$ in diameter. Ultrasonography is slightly more specific than CT scanning for liver metastases, the figures varying between $94 \%$ and $100 \%$, and $81 \%$ and $94 \%$, respectively. ${ }^{22}$ In a recent study in which ultrasonography, CT scanning and MRI were compared in detecting liver lesions, the sensitivity of MRI was in between those of CT scanning and ultrasonography. ${ }^{25}$ Compared with CT scanning and MRI in the search for abdominal metastases, ultrasonography has the advantage that it is an inexpensive examination without side effects and, if a potential metastasis is found, it is possible to perform a guided fine needle aspiration directly from the tumour. ${ }^{22} 23$

New imaging techniques such as helical CT scanning, breath holding, and millisecond MRI and high resolution ultrasonography may increase the sensitivity for abdominal metastases. ${ }^{26}$ On the other hand, these new methods may reveal tiny nodules of less than $1 \mathrm{~cm}$ in diameter and it may be very difficult to decide by fine needle aspiration whether or not they represent micrometastases. ${ }^{26}$

Ultrasonography is less sensitive than CT scanning in detecting adrenal tumours. ${ }^{27}$ Hence, one could argue that in the present study asymptomatic patients might have a false negative status with regard to adrenal metastases. On the other hand, in a study of 173 patients with lung cancer in which the clinical findings were compared with evidence of adrenal metastases from the $\mathrm{CT}$ scan at the time of diagnosis the authors concluded that a CT scan of the adrenal glands was unnecessary if the findings of a clinical examination were normal. $^{7}$

Ultrasonography and CT scanning are widely used on a routine basis in the search for metastases in patients with lung cancer. As a consequence, one might speculate that the clinical examination may be less thorough as the physician knows that the patients will also have a detailed imaging examination. However, if the clinical evaluation of the patients with lung cancer is the basis for further search for metastases, this should restore the importance of the clinical evaluation.

The retrospective design of our study may have led to impaired quality of the data compared with a prospective design. The intraobserver and inter-observer agreement was rather poor for some of the symptoms and clinical signs recorded from the patients' records. However, in the analyses the symptoms and signs were grouped into categories and the agreement between the categories was acceptable. Nonetheless, our findings need to be confirmed by prospective studies.

In conclusion, this study indicates that a careful clinical evaluation of patients with newly diagnosed lung cancer can identify those who are not at risk of having abdominal metastases found on ultrasonography. Our findings indicate that abdominal ultrasonography is not necessary in patients with a negative clinical evaluation. Such a diagnostic approach in patients with lung cancer will help to rationalise 
expense and minimise the delay between diagnosis and treatment.

1 Samet J. The epidemiology of lung cancer. Chest 1993; 103(Suppl 1):20-9S

2 Engelman R, McNamara W. Bronchogenic carcinoma. $\mathcal{f}$ Thorac Surg 1954;27:227-37.

3 Berge T, Toremalm N. Bronchial cancer - a clinical and pathological study. Histopathology and metastases. Scand $\mathcal{F}$ Respir Dis 1975;56:109-19.

4 Chapman G, Kumar D, Redmond J, Munderloh S, Gandara D. Upper abdominal computerized tomography scanning
in staging non-small cell lung carcinoma. Cancer 1984;54: 1541-3.

5 Grant D, Edwards D, Goldstraw P. Computed tomography of the brain, chest and abdomen in the preoperative assessment of non-small cell lung cancer. Thorax 1988; 43:883-6.

6 Whittlesey D. Prospective computed tomographic scanning in the staging of bronchogenic cancer. F Thorac Cardiovasc Surg 1988;95:876-82.

7 Silvestri G, Lenz J, Harper S, Morse R, Colice G. The relationship of clinical findings to CT scan evidence of adrenal gland metastases in the staging of bronchogenic carcinoma. Chest 1992;102:1748-5

8 Pagani JJ. Non-small cell lung carcinoma adrenal metastases. Cancer 1984;53:1058-60

9 Nielsen ME, Heaston DK, Dunnick NR, Korobkin M. Preoperative CT evaluation of non-small cell bronchogenic carcinoma. AfR 1982;139:317-20.

10 Sandler MA, Pearlberg JL, Madrazo BL, Gitschiag KF, Gross SC. Computed tomographic evaluation of the adrenal gland in the preoperative assessment of bronchogenic carcinoma Radiology 1982:145:733-6.

11 Ramsdell J, Peters R, Taylor Jr A, Alazraki N, Tisi G. Multiorgan scans for staging of lung cancer. Correlation with clinical evaluation. $\mathcal{F}$ Thorac Cardiovasc Surg 1977; 73:653-9.

12 Hooper R, Beechler C, Johnson M. Radioisotope scanning in the initial staging of bronchogenic carcinoma. Am Rev in the initial staging of bronch

13 Quinn D, Ostrow L, Porter D, Shelton D, Jackson D. Staging non-small cell bronchogenic carcinoma. Re- lationship of the clinical evaluation to organ scans. Chest 1986;89:270-5.

14 Salvatierra A, Baamonde C, Llama J, Cruz F, Pujol J. Extrathoracic staging of bronchogenic carcinoma. Chest 1990;97:1052-8.

15 Chauvin F, Trillet V, Court-Fortune I, Velay B, Mazoyer G, Girodet B, et al. Pretreatment staging evaluation in small cell lung carcinoma. A new approach to medical decision making. Chest 1992;102:497-502.

16 Silvestri GA, Littenberg B, Colice GL. The clinical evaluation for detecting metastatic lung cancer. A meta-analysis. Am 7 Respir Crit Care Med 1995;152:225-30.

17 American Thoracic Society. Clinical staging of primary lung cancer. Am Rev Respir Dis 1983;127:659-64.

18 Dunnick NR, Ihde DC, Johnston- Early A. Abdominal CT in the evaluation of small cell carcinoma of the lung. $A \mp R$ in the evaluation of

19 Vas W, Zylak C, Mather D, Figueredo A. The value of abdominal computed tomography in the pre-treatment assessment of small cell carcinoma of the lung. Radiology 1981;138:417-8.

20 Skarin A. Analysis of long-term survivors with small-cell lung cancer. Chest 1993;103(Suppl 3):440-4S

21 Souhami R, Bradbury I, Geddes D, Spiro S, Harper P, Tobias J. Prognostic significance of laboratory parameter measured at diagnosis in small cell carcinoma of the lung. Cancer Res 1985;45:2878-82

22 Fisker RV. Diagnostic possibilities and strategies in the detection of liver metastases. Ugeskr Laeger 1994;104: 2881-6.

23 Fobbe F. Detection and differentiation of focal liver lesions by ultrasound. Farmakoterapi 1993;19:68-80.

24 Armitage P, Berry G. Statistical methods in medical research. 2nd edn. Oxford: Blackwell Scientific Publications, 1987: 474

25 Wernecke K, Rummeny E, Bongartz G, Vassallo P, Kivelitz $\mathrm{D}$, Wiesmann W, et al. Detection of hepatic masses in patients with carcinoma: comparative sensitivities of sonography, CT and MR imaging. AfR 1991;157:731-9.

26 Ferrucci JT. Liver tumor imaging: current concepts. $A f R$ 1990;155:473-84.

27 Abrams HL, Sigelman SS, Adams DF, Sanders R, Finberg HJ, Hessel SJ, et al. Computed tomography versus ultrasound of the adrenal gland: a prospective study. Radiology 1982;143:121-8. 